\title{
La educación ambiental ante el problema ético del desarrollo
}

\author{
The Environmental Education on the Ethical Development Problem
}

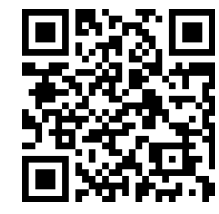

\author{
Carlos Humberto González-Escobar ${ }^{1}$ \\ Universidad de Manizales \\ Manizales, Colombia \\ consultor.carloshg@gmail.com \\ http://orcid.org/0000-0001-5002-0067
}

Recibido 2 de febrero de 2016 • Corregido 30 de marzo de 2017 • Aceptado 18 de abril de 2017

\begin{abstract}
Resumen: El objetivo de esta revisión documental es comprender la complejidad de la problemática ambiental en un entorno de crisis de la civilización, crisis generada por el paradigma científico y las formas de conocimiento imperantes. A partir de esas búsquedas se pretende auscultar el ejercicio pedagógico y el rol de la educación ambiental en la tarea suprema de formar un sujeto cognitivo, ético, político e histórico, con capacidad de asumir los nuevos desafíos planetarios. El orden estructural de este ensayo se centra en una reflexión crítica sobre la crisis ambiental, cuestiona las restricciones de la educación ambiental y el porqué, desde la complejidad, se pretenden incorporar nuevos campos de estudio con un enfoque transdisciplinar. Analiza las causas estructurales del discurso del desarrollo como factores generadores del conflicto social, político y ambiental en Colombia. Estas se reflejan en una crisis institucional, ausencia de Estado y, por tal, de gobernabilidad; para lo cual la educación posibilita un ejercicio pedagógico, en una formación crítica que conduzca a una configuración de la democracia y la gestión pública. El ejercicio del poder, la toma de decisiones y el rol de los sujetos humanos debe hacerse de manera consciente y ética (valores integrativos). Para ello se hace indispensable una ética del desarrollo que comprenda y asuma responsablemente la problemática ambiental. Se entiende, entonces, que el desarrollo soporta una dimensión ética que promueva unas interacciones sustentables entre la sociedad y la naturaleza.
\end{abstract}

Palabras claves: Educación ambiental; ética antropocéntrica; ética biocéntrica; ética del desarrollo; pensamiento sistémico.

\footnotetext{
${ }^{1}$ Administrador de Empresas de la Universidad Nacional de Colombia sede Manizales; Magister en Administración Universidad EAFIT y estudiante del Doctorado en Desarrollo Sostenible de la Universidad de Manizales. Actualmente docente e investigador del CIMAD - Centro de Investigación en Medio Ambiente y Desarrollo Sostenible en la Universidad de Manizales. Dicta en la Maestría en Desarrollo Sostenible y Medio Ambiente el seminario Contexto Socio-Político y Económico Latinoamericano, asesor de tesis de maestría y talleres de investigación. Con dos libros: El desarrollo agroindustrial sostenible de la subregión centro-sur de Caldas y Oferta productiva y competitiva de los municipios de Caldas. En coautoría el libro: Territorio y competitividad.
} 
doi: http://dx.doi.org/10.15359/ree.21-2.14

URL: http://www.una.ac.cr/educare

CORREO: educare@una.cr

\begin{abstract}
The objective of this literature review is to understand the complexity of the environmental issue in a context of civilizational crisis generated by the scientific paradigm and the prevailing forms of knowledge. From this research, the objective is to evaluate the pedagogical exercise and the role of the environmental education in the supreme task of forming a cognitive, ethical, political, and historical subject capable of taking the new planetary challenges on. The structural order of this essay focuses on a critical reflection on the environmental crisis; it also questions the restrictions of the environmental education, and, from the complexity, the reasons for trying to incorporate new fields of study with a transdisciplinary approach. This paper analyzes the structural causes of the discourse of development as factors that generate the social, political and environmental conflict in Colombia. These causes are reflected in an institutional crisis, absence of the State, and, therefore, in governability; for which education makes possible a pedagogical exercise in a critical formation that leads to a configuration of democracy and public management. The exercise of power, the decision-making and the role of human subjects must be accomplished in a conscious and ethical way (integrative values). In order to achieve this, an ethics of development is essential to understand and assume responsibility for environmental issues. It is understood, then, that the development supports an ethical dimension promoting sustainable interactions between the society and the nature.
\end{abstract}

Keywords: Environmental education; anthropocentric ethics; biocentric ethics; ethics of development; systemic thinking.

\title{
Introducción
}

Este ensayo parte del debate ético del desarrollo como discurso y práctica, por su estructura epistemológica, metodología y concepción impuesta en América Latina, discurso construido en otros contextos sociales, desde otro sistema de valores y centrado en un enfoque reduccionista que instituyó un paradigma simple que fracturó las ciencias, y cosificó la naturaleza y a los sujetos humanos.

Para una nueva perspectiva ética del desarrollo en un marco de sostenibilidad ambiental, se propone un cambio de concepciones discursivas y del rol preponderante de la educación ${ }^{2}$ ambiental para asumir la formación crítica de los seres humanos, como sujetos que comprenden la multidimensionalidad y complejidades de los problemas ambientales y la crisis planetaria. El desafío humanitario, científico, transdisciplinar y educativo de una formación integral y ética, en tanto sujetos cognitivos y políticos que comprenden y asumen un compromiso con el desarrollo sostenible de sus territorios.

${ }^{2}$ Etimológicamente la palabra educación viene del latín educare, que quiere decir criar, alimentar, nutrir y del término exducere que significa sacar afuera. Para este ensayo se asume el concepto de exducere por que se trata de contribuir a desarrollar las capacidades de los sujetos humanos al provocarles sus propias reflexiones, sus búsquedas y un análisis critico de su propia realidad y, en particular, la comprensión de las complejidades de la problemática ambiental de su territorio. 
El ámbito amplio de una educación para el desarrollo sostenible ${ }^{3}$ rompe con los enfoques restringidos de la educación en sus procesos formativos en las escuelas y sobre temas restringidos a lo meramente ambiental, como lo que se plantea con respecto a la incorporación de 15 campos o áreas adicionales, en las que se incluyen la paz, la salud, la urbanización sostenible, la economía del mercado, etc. (Macedo, 2005).

Esta preocupación por ampliar los horizontes problematizadores de la crisis humanitaria y social es un buen intento por un abordaje sistémico de la complejidad de las condiciones planetarias, que implican tener en consideración temas como la paz, que para nuestro contexto tiene bastantes implicaciones e interpretaciones.

Si se toma la paz como un tema referente de la educación para el desarrollo sostenible, se ahonda en causas estructurales del conflicto nacional, como los asuntos de la tierra, su particular situación de concentración de la propiedad, en contraste con la exclusión de productores agrarios (grupos campesinos, indígenas, afrodescendientes) por fenómenos sociales, políticos, presión de diferentes grupos armados, ambientales y económicos.

Este solo tema dentro de la crisis en Colombia muestra hoy un panorama lúgubre frente a la restitución de tierras; las sentencias emitidas a favor de las victimas es solo el 1,7\% del total de reclamos que alcanza 54.000 solicitudes (3,4 millones de hectáreas), por tanto, apenas se han resuelto 964 solicitudes, de las cuales 927 fueron a favor de las víctimas. De estos terrenos en litigio, el 53\% corresponde a baldíos propiedad de la Nación. Entre tanto, las víctimas están siendo asesinadas, amenazadas o expulsadas para evitar las reales reclamaciones, que pueden ser 360.000, lo cual significa que únicamente el 15\% ha presentado oficialmente solicitudes de reclamo (Sierra, 2014).

Aquí surge una demanda a la educación como un ejercicio pedagógico de formación critica y consciencia de la dimensión humanista, social y política del Estado, y de las instituciones (todas las estructuras y formas de organización y gestión) públicas y privadas. Para superar las causas de esta crisis, se requiere un cambio en el compromiso y comportamiento ético (la consciencia del poder) más del lado de los sectores dirigentes que de la propia comunidad, en los términos de quienes tienen el control y la capacidad de asumir sus verdaderas responsabilidades.

Ya Morin exponía sus planteamientos de una antropoética (Morin, 1999) desde las posibilidades de que el ser humano tome decisiones de manera consciente, para lo cual remite a la interacción del individuo con la sociedad y la especie en una condición humana capaz de comprender y actuar en un mundo complejo. A esta interacción plagada de humanidad ulterior debe encontrarsele los senderos bióticos de la vida en constante consciencia con su entorno natural.

3 "[Ante] una sociedad al borde del desastre ecológico la universidad debe desarrollar una depurada conciencia ecológica" (Santos, 2010, p. 275). En su responsabilidad social, la universidad debe jugar un rol protagónico en la educación de sujetos cognitivos, históricos y políticos frente a los conflictos ambientales y la crisis de la civilización. 
doi: http://dx.doi.org/10.15359/ree.21-2.14

URL: http://www.una.ac.cr/educare

CORREO: educare@una.cr

La educación ambiental pretende recoger las iniciativas de los problemas ecológicos derivados de la racionalidad instrumental y la hiperindustrialización, para generar un pensamiento comprensivo sobre las consecuencias de los fenómenos económicos, sociales y ambientales, para rescatar los valores integrativos como conductores de las relaciones e interacciones armónicas entre los sistemas sociales y la naturaleza.

La racionalidad de los sujetos humanos no pasa solo por el uso de su capacidad de pensamiento, sino también por su capacidad perceptiva, en consideración espiritual a las sensaciones, los afectos y las subjetividades, lugar posible de horizontes y sentidos para la comprensión sistémica de la vida.

La educación, por tradición, se ha concentrado en la formación del sujeto humano como eje fundamental del desarrollo, en una clara posición antropocéntrica, para luego cambiar su orientación hacia las preocupaciones por la ecología planetaria (Novo, 2009). Este cambio surge de la lectura crítica de las consecuencias de un proyecto modernizante que somete la naturaleza y a los seres humanos como objetos de mercancía.

A través del proyecto de modernidad, se ha impuesto un discurso del desarrollo, que hoy se hace evidente con uno de sus instrumentos, la globalización, que se presenta como la estrategia de universalización de la modernidad. Este discurso está compuesto de representaciones, imaginarios y prácticas de corte euro-céntrico con capacidad de influenciar a las sociedades del sur desde ese eje geo-económico y político del mundo.

El modelo de sociedad tratado de implementar está prefigurado en industrialización, urbanización, economías de escala, educación y valores culturales modernos (Escobar, 2007); la expresión del modelo económico capitalista y esquemático del pensamiento racional simple y netamente instrumental.

Si se trata de armonizar las interacciones de los sistemas sociales con la naturaleza, es necesario encontrar un nuevo discurso del desarrollo, en donde converjan los planteamientos antropocéntricos con los planteamientos biocéntricos ("ecocéntrico"). En ese rol, la educación ambiental tiene la responsabilidad de asumir una transformación social y aun institucional para reorientar el conocimiento científico con los nuevos enfoques alternativos al desarrollo.

Las ciencias sociales, como la economía, tienen una responsabilidad histórica con la concepción y gestión del modelo de desarrollo imperante. Su concepción economicista del desarrollo -ligada a la oferta y demanda de mercancías, al privilegio del mercado por encima de las connotaciones humanas y ambientales, a la observación sesgada de la realidad y a su determinismo- ha atomizado el pensamiento y a la comunidad científica, la cual, a su vez, ha sido absorbida por el capital que le define su rumbo y le asigna roles. 
Es válido buscar y encontrar una perspectiva del conocimiento integral de los fenómenos sociales y naturales, superar las rupturas metodológicas y epistemológicas del conocimiento y de sus nuevas formas de expresión tecnológica e innovadora. Como el encontrar los elementos y “pautas de una cognición ecológica que permita una ecología cognitiva” (Rodríguez, 2005, p. 24), se trata de comprender y entender las relaciones ecológicas con un sistema de pensamiento integral del ser humano.

El ser humano como sistema psíquico que actúa en un escenario social y natural con su carácter interdependiente, al decir de Morin (1999), un ser eco-dependiente, o para llamarlo en la perspectiva sistémica e integradora, un ser "eco-interdependiente", en el sentido de que incorpora cognitivamente el sistema natural y biótico como parte integral de su mismo ser, pero que en sus actuaciones tienen capacidad autopoiesica ${ }^{4}$ e interdependiente. Se leerá, entonces, en las posibilidades de interacción y equilibrio entre los sistemas vivos, a partir de las connotaciones ético biocéntricas.

En ese sentido, la búsqueda incesante de una dimensión humanitaria en el ser humano y una dimensión de la esencia de la vida, en la cual deberá tener cabida no solo como ser vivo, sino también todas las demás formas de vida que habitan el planeta (Novo, 2009). La formación consciente de los sujetos humanos se le asigna a la pedagogía, en particular a su disciplina, la educación. Ella tiene el reto de su transformación integral, en sus ámbitos intelectuales, morales y éticos con el desarrollo, no solo desde la perspectiva de hacerlo incluyente y digno, sino de una sociedad y una naturaleza en armonía con todos los sistemas vivos.

Esa apuesta por la armonía de los sistemas vivos se le confiere a la ética biocéntrica, la cual pretende considerar a la naturaleza y a sus seres vivos como moralmente relevantes, entendida como una ética que destaca la vida en todo organismo individual, de esta forma se ubica a los sujetos humanos no como el centro de esa relación, sino como un ser más en interacción con la naturaleza (Leyton, 2009). La ética biocéntrica trata de trascender los problemas humanos para comprender las condiciones de vida de un colectivo de intraespecies, la especie humana y su capacidad de convivencia con otras especies vivas.

El conocimiento del contexto (plano real) surgido de un proceso de adentrarse en las profundidades del entorno ambiental genera condiciones de refuerzo para modificar las actitudes que los individuos tienen sobre este, lo que conlleva a cambios en sus comportamientos

\footnotetext{
${ }^{4}$ En referencia a la organización autopoiética, Maturana, citado por Rodríguez y Torres (2003), la designan por “la característica más peculiar de un sistema autopoiético es que se levanta por sus propios cordones y se constituye como distinto del medio circundante a través de su propia dinámica, de tal manera que ambas cosas son inseparables" (p. 113). Las propiedades del sistema autopoiético son: autonomía, emergencia, clausura operativa, auto-construcción de estructuras. Autopoiesis significa la "determinación del estado siguiente del sistema a partir de la estructuración anterior a la que llegó la operación (p. 115).
} 
doi: http://dx.doi.org/10.15359/ree.21-2.14

URL: http://www.una.ac.cr/educare

CORREO: educare@una.cr

(Benayas, 1992; Ransey y Rickinson, 1976; Stern, 2000, citados en (Vega y Álvarez, 2005). Se espera que el hecho de tener una información calificada y una apropiación del conocimiento sobre las características del entorno conduzca a desarrollar conductas soportadas en valores ambientales asumidos de manera espontánea y libre.

Para el efecto se propone un sustento teórico para la educación ambiental que se convierte en su referente del conocimiento; este referente, en consonancia con las perspectivas del pensamiento holístico, trata de abordar dos ideas-fuerza: 1) El medio ambiente como sistema. 2) La complejidad ambiental y el desarrollo sostenible en la globalización (Vega y Álvarez, 2005).

Para el abordaje del medio ambiente se incluye tanto el contexto de la naturaleza como las relaciones socioculturales, que actúan en procesos de interacción permanente en las que los sujetos humanos habitan de manera condicionada; pero, a su vez, condicionantes del sistema. Esa característica sistémica permite entender que los problemas ambientales se asumen interdisciplinariamente para comprender su complejidad, su constitución como una totalidad organizada en la que cualquier cambio en una de sus partes afecta a las demás.

La concepción de la EA no se reduce a formar una ciudadanía para "conservar la naturaleza", "concienciar personas" o "cambiar conductas", se le asigna una tarea retadora: es educar para cambiar la sociedad, que se asuman actitudes y pensamiento hacia un desarrollo humano en consonancia con su compromiso planetario de sustentabilidad ambiental. Esto implica incorporar una ética socioambiental a partir de la cual se asume la responsabilidad en la formulación y gestión de políticas públicas para el desarrollo, pero con un sentido real de participación democrática.

La educación ambiental sostenible, según Novo (2000, citado por Vega y Álvarez, 2005, p. 12) tendría como "reto no sólo de contribuir al desarrollo sostenible, sino de 'inventar' fórmulas de sustentabilidad aplicables en los diferentes contextos y ayudar a los sujetos a descubrir nuevas formas de vida más acordes con un planeta armónico", de allí se deriva un discusión conceptual y a profundidad que no es el tema de este ensayo, pero que contribuirá en el futuro a dilucidar las cuestiones epistémicas del desarrollo y su asimilación, se trata de si este es: ¿sostenible o sustentable u otro?

Se pueden evidenciar rupturas y transformaciones en la perspectiva cognitiva y del pensamiento ambiental, como hacer transición de una ética antropocéntrica a una ética biocéntrica, tema de interés en este ensayo, en el que el pensamiento sistémico basado en valores integrativos podría entregar los elementos conceptuales de comprensión de la complejidad de la naturaleza y su interacción con los ecosistemas sociales y culturales, en lo que se entiende una nueva dimensión paradigmática de la ciencia y el conocimiento. 


\section{La educación ambiental y el dilema ético del desarrollo}

La ética y su objeto de estudio la moral son dos categorías que se abordan ahora desde el concepto de la territorialidad en la perspectiva de lo ambiental. ¿Es posible una ética ambiental que incorpore la territorialidad en su integralidad y en sus distintas dimensiones?

La crisis del proyecto de modernidad ha sido planteada en distintos escenarios para connotar los desequilibrios y rupturas en el entorno social, cultural, político, económico, científico, humano y, por tanto, en lo ambiental.

Esa apuesta de la modernidad demostró su incapacidad para leer las complejidades humanas y sus interacciones con la naturaleza, la racionalidad permitió unas lecturas y actuaciones limitadas de las formas de apropiación y sentido de vida en el mundo.

La eticidad tiene dos elementos: el yo dialéctico y contradictorio consigo mismo, la otredad multidimensional y uno que se incorpora, la territorialidad (Noguera, 1996). Esta perspectiva de la ética entiende las posibilidades del lenguaje, la comunicación e interacción permanente como constructora de la dialéctica del sujeto, por tanto, de afirmación de las subjetividades y de las intersubjetividades. El territorio es construible desde todas las posibilidades de interacción del sujeto con los otros seres, con la naturaleza y demás artefactos, estamentos, espacios e instituciones que establecen en esa configuración planetaria.

La pérdida de territorialidad, el desapego, la humanidad sin identidad, la homogeneidad del sujeto promovido por los artefactos de la comunicación en la cotidianidad, las tecnologías que desbordan los espacios íntimos humanos para colocarlos en la virtualidad de la ignorancia colectiva; esto es, la pérdida del sentido de pertenencia al lugar y su propia historia de ubicación con el territorio es la forma presentada de desterritorialidad, de colocación del sujeto por fuera del ciclo vital con su terruño. El dilema por su sentido de vida activa en el lugar o su deslocalización permanente con sus congéneres y su espacio de vida.

La perdida de territorialidad hace ajeno al sujeto con su propia historia, su cultura, sus espacios de vida natural; sus responsabilidades y compromisos latentes con el entorno se confunden por el avasallamiento de la información, el diario intercambio de imágenes; datos e información saturan su capacidad cognitiva, su ubicación en su propia realidad, configurando historias nuevas ajenas a sus sentidos y su lugar. Ganan preponderancia hechos lejanos de su esfera personal y colectiva para atender sucesos y actos de otras esferas, o atendiendo desde las percepciones y sensaciones pasivamente lo que la oferta mediática y comunicacional le entrega.

La disolución del yo, propio de las sociedades en la modernidad, basado en los patrones de la racionalidad, perdió credibilidad y es fuente de descontento. Es el mito del intelectualismo y de los ideales científicos, hoy cuestionados y enfrentados a críticas por su orientación instrumental y al servicio del eficientísimo productivista, por tanto, alejado de una propuesta humanista y de desarrollo sostenible. 
doi: http://dx.doi.org/10.15359/ree.21-2.14

URL: http://www.una.ac.cr/educare

CORREO: educare@una.cr

El sujeto intelectual del paradigma cartesiano sustentó la evolución de las ciencias y las tecnologías modernas, esa orientación privilegió el estudio y transformación de la materia, desconectado de su entorno humano, social y ambiental. La educación privilegia las capacidades y habilidades intelectuales para el trabajo operativo y la producción.

El mundo de la diferencia, la otredad y las alternativas busca un rescate del materialismo impuesto, el encuentro con el sentido de humanidad, la dimensión compleja del ser y saber humano en su interacción con el entorno ambiental.

El sometimiento de la educación a los planes curriculares de acumulación de información, transferencia de la enseñanza en los espacios del aula, la capacidad del intelecto para asimilar eficientemente los datos y signos entregados por el personal docente son una demostración del imperio de la racionalidad instrumental por encima del desarrollo del potencial autónomo y del descubrimiento propio del estudiantado para su aprendizaje.

Una posibilidad de ampliar la razón y el intelecto humano es la recreación de los espacios de reflexión y aprendizaje con nuevos acontecimientos lúdicos, artísticos, apertura al mundo de las ideas y la creatividad, la exploración de los hechos, los objetos y de lo material y lo inmaterial. Las relaciones del estudiantado con su entorno para identificar ese mundo de vida biótico, la naturaleza y el cosmos, en interacción con sus sensibilidades, percepciones y su mundo interior.

La educación ambiental debe establecer un horizonte de sentidos, percepciones, sensibilidades y conexiones de los sujetos humanos con los problemas ambientales; estas relaciones e interacciones son el basamento para la apertura consciente y la comprensión de su complejidad. Entender las dinámicas de la naturaleza, las interacciones humanas y sociales, y los procesos antropocéntricos debe conducir a generar actitudes de respeto y valoración del medio. La educación ambiental asume la responsabilidad de compartir conocimientos para "comprender los fenómenos ambientales, en la formación de un individuo que se reconozca y reconozca a los demás en el medio, a través del sentido de pertenencia y contribuya, de esta manera, a la construcción de criterios de identidad y por ende a la transformación de una sociedad que tenga como uno de sus ejes fundamentales la calidad de vida" (Torres, 1996, p. 43); una educación ambiental para la formación en valores para la convivencia, la tolerancia, las diferencias, la solidaridad, la participación, la equidad, y la justicia.

En la perspectiva ambiental, la vida no se explica únicamente desde la biología y las ciencias naturales, es a partir de ella que se pueden establecer nuevas acciones e interacciones entre el sistema social y el ecosistema natural.

La cultura humana se ha ubicado por equivocación en una orilla diametralmente opuesta a las dinámicas ambientales y, por tanto, de la esencia de la naturaleza. La perspectiva externa de la ubicación alejada del entorno ambiental, su lugar en el contexto de la imaginación humana es exterior a su pensamiento y, por ello, debe ser objeto de estudio, de observación, 
de contemplación. Ese contexto externo no tiene evidencias claras para entender sus lazos comunicantes, en donde se ubica la trama de la vida, para señalarse en un lugar mental y físico externo, susceptible de perderse en el olvido. Este es el espacio de lo público, es abstracto y sin sentido de apropiación, por lo cual no hay quien asuma la responsabilidad colectiva por su devenir futuro; entre tanto es usufructo como recurso para los sistemas de transformación productiva y exploración tecnológica de sus entrañas.

El ser humano en posesión de objetos materiales, acumulador de mercancías es la muestra de su dominación por el precio y el mercado puesto a sus deseos perdidos, necesidades creadas e ilusiones prefabricadas en los centros del diseño y producción. Los nuevos valores y símbolos del poder económico, artefactual y tecnológico, lo hacen deslocalizar de su lugar en la tierra. La confusión entre el consumismo desbordado de objetos y mercancías, la preponderancia del mercado por encima de las condiciones humanas más fraternales lo coloca en el centro de la oferta y la demanda, perdiendo todo sentido de vida y de su corresponsabilidad con la naturaleza.

El territorio obtiene preponderancia como constructo social, no como el mapa (la piel del territorio) ni sola composición ecosistémica, obtiene un protagonismo social cuando existe una apuesta de construcción colectiva de su desarrollo, pues en ella convergen territorios no solo compuestos de sus hechuras físicas, materiales y bióticas, sino como el lugar de encuentro de las diferencias y del sentido de la vida del ser humano.

La sociedad es el constituyente del horizonte colectivo de los seres humanos que habitan, pertenecen y se identifican con un territorio en particular. Seres humanos que interactúan con sus congéneres, en calidad de sujetos sociales y políticos del territorio.

La cultura en sus dimensiones complejas ha entrado en una pérdida de sus ejes centrales y su propia orientación, sus valores están fracturados, sin sentido. Lo sagrado de la vida se derrumba ante la avalancha mercantil. Debe construirse una bioética, una perspectiva multidimensional del biocentrismo. La ética como imperativo humano en interacción con la ética de la vida natural.

Una cultura que comprenda y esté en capacidades de defender los ecosistemas y gestionar un desarrollo sustentable o sostenible desde una perspectiva ética biocéntrica deberá formarse culturalmente a partir del ambiente, en sus multidimensiones y complejidades, es una ambientalización de la cultura y, por tanto, de la educación.

La introducción de la dimensión ambiental en los ámbitos del conocimiento y la vida cotidiana de nuestra cultura implica revoluciones trascendentales que no son asumidas por la estructura actual de la educación, la ética, la política, la ciencia y la tecnología. Introducir la dimensión ambiental implica el viraje de la visión compartimentada del mundo de la vida, a la visión integral, compleja y holística, que las estructuras de la cultura moderna no pueden soportar, por ser estructuras que tienen como característica esencial la escisión. (Noguera, 2004, p. 28) 
doi: http://dx.doi.org/10.15359/ree.21-2.14

URL: http://www.una.ac.cr/educare

CORREO: educare@una.cr

\section{¿Tiene el desarrollo incorporada la dimensión filosófica de la ética?}

Lo natural, en sentido griego, no era solo lo que está allí dispuesto fácticamente, sino cualquier tipo de criatura, de hechura, de realización. Por tanto, algo poiético y físico como un amanecer (el despunte del alba), un atardecer, la construcción de un santuario, la realización de un poema, una canción, un dialogo entre el ser y sus retos son naturales (Cubillos, 1996). En esa perspectiva, la dimensión de lo natural adquiere unos atributos y amplias formas de comprensión e interpretación, porque en ella caben los más amplios ámbitos del contexto propio de la natura, como también todas las posibilidades estéticas y artísticas humanas; se podrá, entonces, observar con atención la perspectiva objetiva como también la subjetiva de las interacciones de lo humano con la naturaleza ${ }^{5}$. La naturaleza era "sujeto" porque el propio hombre es naturaleza ${ }^{6}$, por tanto, el "objeto" es parte de su esencia.

En la modernidad, la relación entre ecosistema y cultura es más compleja, el sujeto rompe la autonomía del mundo natural, sometiéndolo al cumplimiento de una misión instrumental del desarrollo, la cosificación de la naturaleza, un recurso infinito y explotable insaciablemente.

La búsqueda haideggeriana de un sujeto que posibilite el cotidiano actuar y el cotidiano pensar "en" y "con" el mundo, se convertirá en tarea imprescindible para todo ideal de alternatividad al desarrollo.

Los debates a partir de $1995^{7}$ sobre el desarrollo han sido más asiduos y se han referido a preguntas sobre su devenir ético. Esas preguntas al desarrollo sobre su comportamiento ético hacen hincapié en los valores que lo soportan, es así como al desarrollo se le cuestionan sus condiciones éticas, pues no se limitan a componentes técnicos, económicos o de otro orden.

La globalización crea nuevos"valores"y destruye otros existentes, genera graves distorsiones, como lo son los procesos de acumulación de riqueza y la profundización de las exclusiones e inequidades, incrementa las libertades de operación del mercado y restringe las intervenciones o participación de los Estados en su regulación. Esa misma libertad empresarial ha facilitado los procesos extractivos y explotación desaforada de la naturaleza como un recurso más, sin observancia de las consecuencias catastróficas al ecosistema vida y a los mismos seres humanos.

En 1965 Denis Goulet hacia un examen a los temas claves del desarrollo, desde los problemas que identificó (Goulet, 1999):

\footnotetext{
${ }^{5}$ La filosofía de la naturaleza, a veces llamada filosofía natural o cosmología es el nombre que recibió la rama de la ciencia que hoy conocemos como física hasta mediados del siglo XIX.

${ }^{6}$ Para los griegos el "objeto" era todo lo proyectado por el "yo". Una relación profunda entre el sujeto y el objeto, no se entendía como asuntos separados.
}

${ }^{7}$ En 1995 fue la fecha en que se público la edición en inglés de Ética de desarrollo. 
- La incidencia de los bienes materiales sobre el bien•estar humano;

- La subordinación del interés particular [sobre el interés general (el bien universal)];

- La jerarquía de las necesidades y el uso de recursos para satisfacerlas;

- Las consecuencias prácticas de la Solidaridad [sic] universal;

- Las distintas opciones del presente, teniendo en cuenta el futuro;

- El juego práctico del poder y el no-poder, en los espacios construidos entre la libertad, la igualdad y la eficacia... (p. 12)

En este examen se trata de hacer una relación de la ética con otras disciplinas y ciencias, como la economía, la política, el orden social, el derecho, la cooperación (sistemas, políticas, instrumentos y agentes), el ejercicio del poder y demás actuaciones humanas desde quien dirige y los agentes propios del desarrollo.

Recuperar el sentido moral de lo público, en momento de crisis de valores y proliferación de "leyes" y juicios que no se ejercen desde los principios rectores de la ética pública y más en el orden de atención a intereses privados.

El desarrollo trata sobre las complejidades humanas, en las posibilidades de obtención de una vida digna para los seres humanos, la justicia y la equidad, así como de las nobles y armónicas interacciones con la naturaleza. Ahí es donde se centra la discusión ética, dada la necesidad de consciencia colectiva, de compromiso y responsabilidad como valores rectores que orienten las decisiones y actuaciones desde el conocimiento científico, la producción y la gestión propia del desarrollo.

El desarrollo está fundamentado en valores..., el desarrollo debe estar soportado en valores humanos esenciales, por tanto, debe ser válido para todas las culturas y grupos sociales. Es el ascenso de todas las personas y sociedades hacia la humanidad total (Lebret, citado en Goulet, 1999).

Para el año 1945 se acepta en el desarrollo la disciplina de la economía, pero con una visión técnica de la planificación de recursos y de la ingeniería social, dirigida a potenciar el crecimiento económico autosostenido que permita a la ciudadanía el consumo de masas. Se acepto el crecimiento económico como la búsqueda de la auténtica vida. Para los primeros entes "desarrollistas", el crecimiento económico era la prioridad, hacerlo de forma veloz y sin revisar en costos sociales y humanos. Crearon su propio sistema de valores dentro de la esfera economicista y mercantilista de la producción por la producción. 
doi: http://dx.doi.org/10.15359/ree.21-2.14

URL: http://www.una.ac.cr/educare

CORREO: educare@una.cr

En cuestiones de cambio social, los desacuerdos éticos más agudos surgen en relación con los criterios con los cuales se obtienen los fines, y los sistemas de medios que se emplean para obtener los objetivos. Es la tradicional discusión entre medios y fines, cargada hoy de innumerables distorsiones éticas y morales en dirigentes, actores estratégicos y sociales diversos.

La obtención de los fines a cualquier costo (no importa por qué medios) es no solo permisiva y antihumanista, sino también perversa en su sentido maquiavélico para detentar poder o adquirir acumulación de capital y material; en ese punto se encuentran las ventajas de dirigentes omnímodos y detentadores del control hegemónico del sistema capital. Esa racionalidad pragmática y netamente instrumental preponderá a asuntos privados, crecimiento de la riqueza y atesoramiento desbordado por encima de intereses de lo colectivo y lo público; esto establece una enorme distancia comprensiva y de estilos de actuación.

Las racionalidades son técnicas, políticas y éticas; lo técnico tiene como fin conseguir que se obtenga las cosas, el logro; en la política asegurar la supervivencia de las instituciones, guardar las reglas de juego; en la ética es promover, crear o defender ciertos valores por sí mismos. Se propone una interacción entre las tres racionalidades en la búsqueda del deber ser.

La discusión ética se centra en los valores, se requiere debatir más que de una ética ambiental avanzar hacia una ética del desarrollo, bajo el influjo de un nuevo discurso pertinente y sustentado en valores integrativos, que definen el pensamiento sistémico y las complejidades de las interacciones entre el ecosistema y los sistemas culturales y sociales (las sociedades específicas del lugar).

El terreno ético que se propone aborda los valores que sustentan la naturaleza y los valores que soportan y sirven como guía de comportamiento de los seres humanos con respecto a esas interacciones permanentes con su entorno (Gudynas, 2004). Al proponer que la naturaleza es sujeto de valor intrínseco, no se está aceptando un valor de uso o un valor de cambio, no tiene un precio en el mercado, se está refiriendo a sus connotaciones de vida, a su ecosustancialidad como sistema vivo, del cual se deriva una importancia vital para el ecosistema, ya que son esenciales para la actuación ecológica del planeta.

El dilema de una ética de desarrollo se orienta a las discusiones históricas sobre los problemas ambientales surgidos del sistema de decisiones humanas, de sus prácticas culturales, en ella tienen cabida las conexiones de la trama de la cultura y la trama de los valores éticos, en lo que supone un diálogo ambiental con un universo interdisciplinar. Incluyen aspectos políticos, ecológicos, económicos, científicos, estéticos y tecnológicos (Ángel Maya, citado en Noguera, 2007). En esa perspectiva sistémica de la complejidad de la naturaleza y las interacciones con el sistema cultural entra en consideración un enfoque más amplio, pues en él aparecen configuraciones estéticas de la concepción del entorno ambiental, en lo que se supondría un dialogo estético de la naturaleza y lo humano, tanto por su capacidad de observar y disfrutar de las consideraciones paisajísticas, contemplativas y estéticas que proyecta la misma naturaleza, 
sino por las posibilidades nuevas que el ser humano tiene de comprender, recrear y reinterpretar el entorno y la naturaleza. Es un reverdecer de la poiética del lugar, una puesta en escena del arte en consideración con la ética de la vida.

\section{La educación ambiental sistémica en una perspectiva de la ética y del desarrollo -a partir de la trama de la vida- (Capra, 1998)}

Las conexiones humanas son las mismas conexiones que nos relacionan con la naturaleza, son una misma cosa, existe una imbricación del sistema de vida, una ligazón universal y planetaria que nos hace sujetos responsables de las consecuencias de nuestros actos y de nuestra ignorancia sobre comprender los que nos ata eternamente con nuestra Gaia y nuestros congéneres. Una ética del discurso del desarrollo, una alternatividad que nos convoca en medio de las diferencias.

Los problemas globales y la crisis humanitaria a la que asistimos afectan la biosfera y la vida humana; su profundidad debe llevarnos a estudiar los problemas en tanto conllevan distorsiones en los seres humanos en su salud, en sus actuaciones cotidianas, en sus relaciones sociales y en la restricción a su comprensión, deliberación y reflexión crítica.

La dimensión de la crisis deviene en lugares específicos, a ellos les asiste unas consecuencias directas y particulares desde su perspectiva biofísica, natural, social, económica, educativa, tecnológica, estética y cultural. Estudiar a profundidad esas connotaciones y consecuencias en su entorno biosistémico y ecocultural mostrará otras realidades, como, por ejemplo, la extracción de recursos del subsuelo, para el caso de la gran minería que sustrae el petróleo, el oro y otros minerales.

Si existe preocupación por las afectaciones en los seres humanos, las plantas y los animales en el lugar, esto simplemente no muestra el panorama complejo y sistémico de ese territorio, si bien se requiere de la obtención de mayores niveles de investigación y conocimiento, estos deben abordar una dimensión sistémica para comprender el problema en su integralidad. Ese reto es tanto para la comunidad científica natural, como para las ciencias humanas y sociales, quienes deben emprender un esfuerzo mayúsculo de carácter transdisciplinar para desentrañar los problemas ambientales y sociales derivados de la sobreexplotación del planeta tierra y del ecosistema en general.

Los desequilibrios de la economía global, dada la concentración de capitales y de poder en centros urbanos y de grupos empresariales (familiares) y del otro lado sociedades que soportan la carga de las deudas al sistema financiero global, con poca capacidad de maniobrabilidad ante las complejas situaciones sociales y productivas de sus comunidades galopan en un escenario de restricción cotidiana de libertades, en un enjambre de conflictos urbanos y suburbanos, en donde la violencia es la expresión manifiesta de una crisis profunda y estructural del desarrollo. 
doi: http://dx.doi.org/10.15359/ree.21-2.14

URL: http://www.una.ac.cr/educare

CORREO: educare@una.cr

Muchos de los problemas complejos de nuestras sociedades tendrán solución, pero estas surgirán de un cambio radical de las percepciones, el pensamiento y del sistema de valores que lo sustente. En especial de los grupos dirigentes responsables de las más importantes decisiones productivas, económicas, tecnológicas, sociales y también por su capacidad de influencia y poder, las decisiones están revistadas de un alto carácter político.

Esto implica la asunción de una ética del desarrollo en las esferas del poder, revestida, en su esencia, de un marco de principios y valores que guíen el pensamiento y la acción de los cuerpos dirigentes, cualquiera que sea su espacio vital de interacción. Las instituciones sociales, en su constitución, configuración y estructura deberán tener un funcionamiento para dar respuesta pertinente y oportuna a las complejidades sociales de nuestro tiempo, a los retos de inclusión social e inclusión planetaria de los problemas del sistema biótico.

Del paradigma Kuhniano de la ciencia, se pasa al paradigma social complejo que se propone en la trama de la vida. Mientras el paradigma científico se centra en sus propios esquemas de valores, episteme, conceptos, técnicas y argumentos que dan lugar a cambios de racionalidad y de pensamiento de una comunidad científica; el paradigma social construye su propia estructura conceptual, valores, percepciones y prácticas, pero dentro de un entramado social, en el escenario de una sociedad determinada que los comparte. Esa sociedad asume una comprensión y una visión sobre su propio entorno y determina sus propias formas de organización y gestión.

El paradigma dominante se apoya en unos valores y unos conceptos en los que se privilegia la materia y su transformación, la visión del mundo como un sistema cerrado, una maquina en donde el ser humano es parte de su engranaje y sus formas de operación, y la naturaleza hace parte de sus componentes de entrada al sistema (in put), ya sea materia como insumo, energías, información y demás recursos para mover la maquina productiva, de la cual se arrojan al ecosistema sus artefactos (out put), nuevos datos, información, tangibles e intangibles que irrumpen en la esfera biótica y en el entorno social y humano, cambiando valores, promoviendo el consumo de la naturaleza y al propio hombre como mercancías, de un mercado abierto a todas las posibilidades de usufructo desbordado.

El paradigma social tiene una perspectiva holística e integral de la observación de la realidad de su entorno social, que denomina una ecología profunda, en la que los problemas y fenómenos se asumen desde su interdependencia y sus conexiones e interacciones entre los diferentes sistemas y subsistemas que componente este entramado del macrosistema biótico (la naturaleza).

La concepción ecológica (profunda y social) explicaría no solo el sentido sistémico e integral de los fenómenos sociales, más allá de la funcionalidad e instrumentalidad de la operación, procesos y maneras de actuación, explicaría la percepción y sentido de colocación e inserción 
(conexiones) con el entorno social (comunidad) y el entorno natural. Le ecología profunda nos adentra en las comprensiones de mundo por su visión compleja e integral de este como sistema, en sus partes y componentes esenciales, pero más en su capacidad de ver y entenderlos en su sentido de apropiación social, su rol cultural en las comunidades y en su conjugación con las subjetividades humanas, como se percibe y se siente un fenómeno o cosa en una sociedad determinada, pero así mismo como se percibe en la naturaleza, cómo en su entramado incorpora agentes externos o nuevos fenómenos que irrumpen o se conectan a su sistema relacional.

La ecología profunda entiende al ser humano integrado a su entorno natural, y este lo observa no como un objeto externo y alejado de las relaciones humanas, sociales y culturales, sino como simbiosis de vida e interacciones permanentes y dinámicas.

El cambio de paradigma social implica cambios en los modos de pensamiento de grupos dirigentes y actores sociales, en la asunción del ser humano perceptivo, sensible y emocional; así como el surgimiento de nuevos valores. La predominancia del pensamiento y los valores asertivos ${ }^{8}$ hacia los valores integrativos ${ }^{9}$ ha generado un desequilibrio, pues se ha puesto énfasis en las economías de escala, en la productividad y la competitividad, etc.

En el nuevo paradigma se propone un cambio en la estructura social, al pasar de un sistema de poder jerárquico hacia una estructura en red, que significa unas relaciones en sentido horizontal y no en aquel donde se actúa con un poder de influencia sobre los demás seres y menos de imposición de órdenes superiores.

Con la incorporación de una perspectiva ética integrativa y respetuosa de la naturaleza y su relación armónica de los cuerpos científicos, dirigentes y demás sujetos humanos se estará contribuyendo a promover un paradigma social incluyente desde el pensamiento, la percepción y los valores integrativos; sistemas vivos como miembros de comunidades ecológicas pensando y actuando en interdependencia y con sentido integrativo (sí mismo). La conexión entre la percepción ecológica del mundo y los comportamientos humanos está directamente relacionada con actos psicológicos, esa comprensión hace de nuestros comportamientos acciones surgidas de nuestra profundidad consciente y humana, no de las normas y sanciones morales: actuaremos en consonancia y coherencia con valores colectivos, ecológicos y ecosistémicos. En la consideración de una ética biocéntrica, en la que todos los sistemas vivos, humanos y no humanos interactúan de manera equilibrada y armónica.

\footnotetext{
${ }^{8}$ Capra describe como valores asertivos la expansión, la competición, la cantidad y la dominación. Estos valores asertivos están en relación con formas de pensamiento asertivo, entre estos: lo racional, analítico, reduccionista y lineal (Capra, 1998).

${ }^{9}$ Capra señala como valores integrativos los referidos a la conservación, la cooperación, la calidad y la asociación. En relación con estos valores define las formas de pensamiento integrativo, como: lo intuitivito, holístico, no-lineal y sintético (Capra,1998).
} 
doi: http://dx.doi.org/10.15359/ree.21-2.14

URL: http://www.una.ac.cr/educare

CORREO: educare@una.cr

Los sistemas vivos son totalidades integradas en las que las propiedades no son pertenecientes a un elemento en particular, son propiedad del conjunto, en una visión holística. Es una totalidad organizada en la que confluyen las partes en la conformación de una capacidad sinergética del sistema.

“El pensamiento sistémico es ... 'contextual', y puesto que la explicación en términos de contexto significa la explicación en términos de entorno, [por tanto se puede] afirmar que el pensamiento sistémico es un pensamiento medioambiental" (Flacam, 2010, p. 2).

Los sistemas actúan como organismos autónomos, autorregulados y con capacidad de detectar desviaciones de los fines presupuestados se soportan en datos, información y comunicación. Se soportan en la comunicación y el control como elementos de su capacidad de regulación en su interacción con el entorno y en su propia constitución interna (son interdependientes).

Cuando la información contribuya a la autorregulación de un sistema, no siempre conlleva a dominar la inteligencia de quien controla o piensa para el sistema o desde este. La información no es la base del pensamiento, y en realidad la mente humana piensa con ideas, no con información. Esta no crea ideas, las ideas crean información (Roszack, citado por Capra, 1998). Las ideas son patrones integradores que no derivan de la información, sino de la experiencia.

Las máquinas y su capacidad reproductiva de su aparataje, en términos de su capacidad de influir y repetir sus esquemas de operación y rutinas en las mentes de las personas que los manejan constituyen una inquietud. Esa preocupación por el uso indiscriminado de artefactos tecnológicos en los diferentes ámbitos de la vida humana y social están irrumpiendo en los escenarios públicos, pero también en la ruptura de los lazos humanitarios, de la verdadera comunicación con sentido humano, e incluso se convierten en hacedores artificiosos de metalenguajes, relaciones maquínicas y réplica de su estructura y sus lenguajes de comunicación.

Se considera que el uso de las máquinas (artefactos) está afectando la intimidad del sujeto, está empobreciendo su espíritu, hay una pérdida de diversidad cultural derivada del uso excesivo, especialmente grave en la educación. "Cuando se usa un ordenador para aprender, el propio sentido de 'aprender' queda alterado" (Postman, 1994, p. 25).

La GAIA, la Tierra como un sistema vivo autorregulador en la relación entre sistemas vivos y no vivos en esa búsqueda de la armonía de los sistemas vivos y no vivos que permitan el equilibrio dinámico y una construcción colectiva y ecológica de la vida. Un sujeto con pensamiento sistémico, capaz de entender y comprender el comportamiento del ecosistema y de sus responsabilidades intelectuales, culturales y políticas con el futuro del planeta y de las generaciones futuras. 
Las generaciones futuras tendrán la responsabilidad con el planeta y con la vida, para lo cual deberán educarse como ciudadanos y ciudadanas del mundo, esto significa prepararse cognitiva y emocionalmente para comprender los problemas, adentrarse en las causas estructurales y darles solución. Esa educación de una ciudadanía con consciencia ambiental puede lograr, a partir de lo que Carrizosa (2014) denomina la educación ambiental compleja, que plantea como aquella que "forma y capacita [a los sujetos humanos] para comprender la totalidad que nos rodea [el entorno ambiental] y nuestros vínculos con ella, mirándola profunda y ampliamente, analizando y sintetizando, teniendo en cuenta todas las interacciones entre sus componentes, considerando su pasado, tratando de predecir su futuro y de modificarlo y respetando las opiniones y las posiciones de los otros" (p. 265).

\section{Conclusiones}

Se hace necesaria y urgente una educación ambiental orientada al desarrollo sostenible que promueva, desde los valores integrativos, un sujeto consciente, político, histórico y ético.

La comprensión de las dimensiones de la crisis civilización, como crisis planetaria y territorial, una crisis de las ciencias y el conocimiento, en la que está implicada la educación ambiental, en su responsabilidad con la formación de sujetos humanos críticos.

El paradigma imperante de carácter restrictivo, lineal e instrumental tiene lecturas parciales del plano real e histórico; no permite una comprensión de las complejidades de las relaciones e interacción entre los sistemas sociales, como sistemas culturales y el ecosistema natural; de ahí la importancia de un nuevo paradigma complejo e interdisciplinario.

\section{Referencias}

Capra, F. (1998). La trama de la vida: Una nueva perspectiva de los sistemas vivos. Barcelona: Anagrama.

Carrizosa, J. (2014). Colombia compleja. Bogotá: Jardín Botánico de Bogotá José Celestino Mutis y el Instituto de Investigación de Recursos Biológicos Alexander Von Humboldt. Recuperado de https://redjusticiaambientalcolombia.files.wordpress.com/2014/07/ colombia-compleja.pdf

Cubillos, L. F. (1996). Ética ambiental en una recuperación heideggeriana de la gnoseologia clásica (aproximaciones). Luna Azul , 11-20.

Escobar, A. (2007). La invención del Tercer Mundo. Construcción y deconstrucción del desarrollo. Caracas: Fundación Editorial el Perro y la Rana. Recuperado de http://www.cronicon.net/ paginas/Documentos/No.10.pdf 
doi: http://dx.doi.org/10.15359/ree.21-2.14

URL: http://www.una.ac.cr/educare

CORREO: educare@una.cr

Foro Latinoamericano de Ciencias Ambientales, FLACAM. (2010). Cambio de aptitud. La epistemología de la complejidad y el saber del proyecto (Maestría 2009-2010 en Desarrollo Sustentable, Clase 4). [Diapositivas en PowerPoint]. Recuperado de http://www.flacamred.com.ar/centrodocumentacion/documentacion/0092\%20La\%20epistemologia\%20 de\%20la\%20complejidad\%20y\%20el\%20saber\%20del\%20proyecto.pdf

Goulet, D. (1999). Ética del desarrollo: Guía teórica y práctica. Madrid: IEPALA.

Gudynas, E. (2004). Ecología, economía y ética del desarrollo sostenible. Montevideo: CLAES. Recuperado de http://www.ecologiapolitica.net/gudynas/GudynasDS5.pdf

Leyton, F. (2009). Ética medio ambiental: Una revisión de la ética biocéntrica. Revista de Bioética y Derecho, 16, 40-44. doi: $10.1344 /$ rbd2009.16.7966

Macedo, B. (2005). Educación para todos, educación ambiental y educación para el desarrollo sostenible:Debatiendo las vertientes de la década de la educación para el desarrollo sostenible. Santiago, Chile: Unesco, Orealc. Recuperado de http://earthcharter.org/invent/images/ uploads/Macedo,\%20Beatriz.\%20EDS\%20debatiendo\%20vertientes\%20(SPA).pdf

Morin, E. (1999). Los siete saberes necesarios en la educación del futuro. París: Unesco.

Noguera, A. P. (1996). El territorio ético: Desolación cultural y crisis ambiental. Cuadernos de Epistemología Ambiental, 3, 56-74.

Noguera, A. P. (2004). El reencantamiento del mundo. Manizales: PNUMA y Universidad Nacional de Colombia IDEA. Recuperado de http://www.unter.org.ar/imagenes/El\%20 Reencantamiento\%20del\%20Mundo.pdf

Noguera, A. P. (2007). Horizontes de la ética ambiental en Colombia. De las éticas ambientales antropocentristas a las éticas ambientales complejas. Recuperado de http://www.cep.unt. edu/papers/noguera-sp.pdf

Novo, M. (2009). La educación ambiental, una genuina educación para el desarrollo sostenible. Revista de Educación, 195-217. Recuperado de http://www.revistaeducacion.mec.es/ re2009/re2009 09.pdf

Postman, N. (1994). Tecnópolis. La rendición de la cultura a la tecnología. Gutenberg: Editorial Galaxia.

Rodríguez, D. y Torres, J. (2003). Autopoiesis, la unidad de una diferencia: Luhmann y Maturana. Sociologías, 5(9), 106-140. Recuperado de https://doi.org/10.1590/S1517$\underline{45222003000100005}$ 
Rodríguez, J. A. (2005). Condiciones cognitivas para un desarrollo sostenible (Tesis doctoral). Universidad de Gotemburgo. Gotemburgo, Suecia. Recuperado de https://gupea.ub.gu. se/bitstream/2077/16611/5/gupea 2077 16611 5.pdf

Santos, B. (2010). De la mano de Alicia. Lo social y lo político en la postmodernidad. Bogotá: Ediciones Uniandes. Recuperado de http://enlaceacademico.ucr.ac.cr/sites/default/files/ publicaciones/DE\%20LA\%20MANO\%20DE\%20ALICIA Boaventura\%20de\%20Sousa.pdf

Sierra, Á. (26 de marzo de 2014). Restitución de tierras, ¿gota a gota? Semana, Sección Nación. Recuperado de http://www.semana.com/nacion/articulo/cuellos-de-botella-en-procesode-restitucion-de-tierras/381600-3

Torres, M. (1996). La dimensión ambiental: Un reto para la educación de la nueva sociedad. Proyectos ambientales escolares. Bogotá: Ministerio de Educación Nacional. Recuperado de http:// biblovirtual.minambiente.gov.co:3000/DOCS/MEMORIA/MMA-0190/MMA-0190.pdf

Vega, P. y Álvarez, P. (2005). Planteamiento de un marco teórico de la educación ambiental para un desarrollo sostenible. Revista Electrónica de Enseñanza de las Ciencias, 4(1), 1-16. Recuperado de http://reec.uvigo.es/volumenes/volumen4/ART4 Vol4 N1.pdf 